\title{
Genetic and Molecular Characterization of the Human Osteosarcoma 3AB-OS Cancer Stem Cell Line: A Possible Model for Studying Osteosarcoma Origin and Stemness
}

RICCARDO DI FIORE,' DANIELE FANALE, ${ }^{2}$ ROSA DRAGO-FERRANTE' FERDINANDO CHIARADONNA, MICHELA GIULIANO,' ANNA DE BLASIO,' VALERIA AMODEO, ${ }^{2}$ LIDIA R. CORSINI, ${ }^{2}$ VIVIANA BAZAN, ${ }^{2}$ GIOVANNI TESORIERE, ${ }^{1,4}$ RENZA VENTO, ${ }^{1,4 *}$ AND ANTONIO RUSSO ${ }^{2,4}$

'Section of Biochemical Sciences, Department of Experimental Biomedicine and Clinical Neurosciences, Polyclinic, University of Palermo, Palermo, Italy

${ }^{2}$ Section of Medical Oncology, Department of Surgical and Oncological Sciences, Polyclinic, University of Palermo, Palermo, Italy ${ }^{3}$ Department of Biotechnology and Biosciences, University of Milano-Bicocca, Milan, Italy

${ }^{4}$ Institute for Cancer Research and Molecular Medicine and Center of Biotechnology - College of Science and Biotechnology, Temple University, Philadelphia, Pennsylvania

Finding new treatments targeting cancer stem cells (CSCs) within a tumor seems to be critical to halt cancer and improve patient survival. Osteosarcoma is an aggressive tumor affecting adolescents, for which there is no second-line chemotherapy. Uncovering new molecular mechanisms underlying the development of osteosarcoma and origin of CSCs is crucial to identify new possible therapeutic strategies. Here, we aimed to characterize genetically and molecularly the human osteosarcoma 3AB-OS CSC line, previously selected from MG63 cells and which proved to have both in vitro and in vivo features of CSCs. Classic cytogenetic studies demonstrated that $3 A B-O S$ cells have hypertriploid karyotype with 7I-82 chromosomes. By comparing 3AB-OS CSCs to the parental cells, array CGH, Affymetrix microarray, and TaqMan ${ }^{\mathrm{R}}$ Human MicroRNA array analyses identified 49 copy number variations (CNV), 3,5I2 dysregulated genes and I89 differentially expressed miRNAs. Some of the chromosomal abnormalities and mRNA/miRNA expression profiles appeared to be congruent with those reported in human osteosarcomas. Bioinformatic analyses selected 196 genes and 46 anticorrelated miRNAs involved in carcinogenesis and stemness. For the first time, a predictive network is also described for two miRNA family (let-7/98 and miR-29a,b,c) and their anticorrelated mRNAs (MSTN, CCND2, Lin28B, MEST, HMGA2, and GHR), which may represent new biomarkers for osteosarcoma and may pave the way for the identification of new potential therapeutic targets.

J. Cell. Physiol. 228: II89-I20I, 20I3. (C) 2012 Wiley Periodicals, Inc.

The authors declare no conflict of interest.

Riccardo Di Fiore and Daniele Fanale contributed equally to this work.

Additional supporting information may be found in the online version of this article.

Contract grant sponsor: Italian Ministry of Education, University and Research (MIUR) ex-60\%, 2007.

Contract grant sponsor: Innovative Research Projects (University of Palermo, Italy, 2007).

Contract grant sponsor: MIUR-PRIN;

Contract grant number: 2008P8BLNF (2008).

Contract grant sponsor: MIUR;

Contract grant number: 867/06/07/201I.

Contract grant sponsor: MIUR;

Contract grant number: 2223/I2/19/201I.

Contract grant sponsor: MIUR-PRIN;

Contract grant number: $144 / 01 / 26 / 2012$.

Contract grant sponsor: Italian Ministry of Health (2008 and 2009).

*Correspondence to: Renza Vento, Section of Biochemical Sciences, Department of Experimental Biomedicine and Clinical Neurosciences, Polyclinic, University of Palermo, Via del Vespro 129, Palermo 90127, Italy. E-mail: renza.vento@unipa.it

Manuscript Received: 4 September 2012

Manuscript Accepted: 18 October 2012

Accepted manuscript online in Wiley Online Library (wileyonlinelibrary.com): 5 November 2012.

DOI: $10.1002 /$ jcp. 24272 
Osteosarcoma, the most common of primary bone malignancies, is a highly aggressive tumor exhibiting clinical, histologic, and molecular heterogeneity (Tang et al., 2008). Classic cytogenetic studies and array CGH analysis in pediatric and adult osteosarcoma patients have demonstrated that the majority of osteosarcomas are characterized by complex chromosomal abnormalities, with specimens varying from haploid to near-hexaploid, and frequent chromosomal gains and losses, indicating the highly unstable nature of the osteosarcoma cell genome (Bridge et al., 1997; Batanian et al., 2002; Niini et al., 201 I). The tumor, which in about $80 \%$ of cases occurs at sites of rapid bone growth (e.g., the metaphyses of long bones), has an initial peak incidence in the pediatric and early adult population and a second peak incidence in later adult life (Tang et al., 2008). The current standard chemotherapy regimen, which includes cisplatin, doxorubicin, and methotrexate, provides only 65-70\% long-term disease-free survival for osteosarcoma patients without metastasis (Chou and Gorlick, 2006), and there is no established second-line chemotherapy for relapsed osteosarcoma. Thus, there is an urgent need to identify new therapeutic strategies to improve the clinical outcome of patients with osteosarcoma.

Currently, a fundamental problem in cancer research is the identification of the cancer stem cells (CSCs) within a cancer cell population that maintain the malignant potential and determine resistance to therapy (Clarke et al., 2006). Whether CSCs derive from transformed stem cells or result from cancer cells during their progressive development is still an open question (Bapat, 2007). However, CSCs have been isolated from a great number of tumors (Visvader and Lindeman, 2008), and several lines of evidence suggest that tumors contain a small fraction of cells (CSCs) responsible for the initiation, growth, and development of the tumor (Giordano et al., 2007). The discovery of CSCs has changed the role of chemotherapy. Indeed, most tumors recur after apparently successful eradication, likely because CSCs survive and restore tumor growth (Dean et al., 2005); thus, cancer could be caused by CSCs and the treatment of cancer should require their eradication. Importantly, although a number of reports have identified and characterized CSCs in human osteosarcomas (Wang et al., 2009, 20 I I; Rainusso et al., 20 I I; Tirino et al., 201 I; Martins-Neves et al., 20I2), to our knowledge, no human osteosarcoma CSC line has been developed. In addition, the genetic and molecular characterization of human osteosarcoma CSCs has been little explored.

Cancer is considered to be a disease with multiple genetic/ epigenetic changes that lead to chromosomal instability and tumor progression (Lagasse, 2008). Although it has been shown that most cancers are characterized by complex chromosomal rearrangements associated with copy number aberrations (Roschke and Kirsch, 20I0), there is still debate whether chromosomal aberrations are essential for cancer initiation or are an outcome of the tumorigenic process.

We have previously demonstrated that brief treatment (24-72 h) of human osteosarcoma MG63 cells with 3aminobenzamide $(3 A B)$, a potent competitive inhibitor of poly(ADP-ribose) polymerase, markedly reduced their growth rate, promoting osteocyte differentiation (De Blasio et al., 2003). This was accompanied by a reprogramming of gene expression with down-regulation of genes required for proliferation and up-regulation of those implicated in osteoblastic differentiation (De Blasio et al., 2005). However, prolonged treatment of MG63 cells with $3 A B$ (about 100 days) induced osteocyte death accompanied by a progressive enrichment of a new cell population. These cells, termed $3 A B-$ $O S$, are a heterogeneous and stable cell population, which after $3 A B$ withdrawal and serial passages (currently, more than 200) has retained its morphological and antigenic features. $3 A B-O S$ cells show various features of CSCs, including unlimited proliferative potential, an ATP-binding cassette transporter ABCG2-dependent phenotype with high drug efflux capacity, and a strong expression of a large number of genes required for maintaining stemness and for inhibiting apoptosis (Di Fiore et al., 2009). 3AB-OS cells are highly tumorigenic and recapitulate in vivo (xenografted athymic mice) various features of human osteosarcoma, thereby representing a useful model system to test in vivo novel antitumor approaches against human osteosarcoma (Di Fiore et al., 2012). They grow in ultralow-attachment plates at a low density with a high sphereformation efficiency (Di Fiore et al., 2009), and they penetrate Matrigel with 2.6-fold higher invasion ability than the parental MG63 cells. They efficiently transdifferentiate, in vitro, into cells of all three primary germ layers (ectoderm, endoderm, and mesoderm) which demonstrate various functional properties (manuscript in preparation). Overall, these results demonstrate that for the first time we have isolated a human osteosarcoma cancer stem cell line (3AB-OS).

microRNAs (miRNAs) are a large family of non-coding small RNAs of approximately 22 nucleotides that act primarily by targeting mRNAs for cleavage or translational repression (Bartel, 2009). Bioinformatics analyses suggest that up to $30 \%$ of human genes are under the control of miRNAs (lorio and Croce, 2009). miRNAs are important regulators of development and differentiation, and their aberrant expression can lead to cancer or contribute to determine the stemness phenotype (Lu et al., 2005; lorio and Croce, 2009). Although the role of miRNAs in osteosarcomagenesis is largely unexplored, some studies have recently described miRNA in osteosarcoma, identifying miRNA signatures associated with the pathogenesis and progression of osteosarcoma and revealing complex mechanisms of miRNA deregulation (Maire et al., 20I I; Jones et al., 20I2; Kobayashi et al., 20I2).

Our study aimed to characterize the $3 A B-O S$ CSC line at the genetic and molecular level, to identify the molecular mechanisms likely to give rise and maintain CSCs in osteosarcoma. This will permit us to identify new potential therapeutic targets for tailored therapies to eradicate CSCs in osteosarcoma.

Materials and Methods Cell cultures

Human osteosarcoma MG63 cells and human fibroblast HS68 cells were acquired from Interlab Cell Line Collection (ICLC, Genova, Italy) and American Type Culture Collection (LGC Standards, Sesto San Giovanni (MI), Italy), respectively. The human 3AB-OS cells have been produced in our laboratory (Di Fiore et al., 2009) and patented (Pluripotent CSCs: their preparation and use. N. Patent Appln. No. FI2008A000238, December I I , 2008). Cell lines were cultured as monolayers in T-75 flask in Dulbecco's modified Eagle medium (DMEM), supplemented with $10 \%(\mathrm{v} / \mathrm{v})$ heatinactivated fetal bovine serum, $2 \mathrm{mM}$ L-glutamine, and antibiotics (50 U/ml penicillin-50 $\mu \mathrm{g} / \mathrm{ml}$ streptomycin; Euroclone, Pero (Ml), Italy) in a humidified atmosphere of $5 \% \mathrm{CO}_{2}$ in air at $37^{\circ} \mathrm{C}$. The culture medium was changed every 3 days. When cells grew to approximately $80 \%$ confluence, they were subcultured or harvested using $0.025 \%$ trypsin-EDTA (Life Technologies Ltd., Monza, Italy). Cell viability was tested by trypan blue exclusion.

\section{Karyotype analysis}

Karyotype analysis of $3 \mathrm{AB}-\mathrm{OS}$ cells was performed by Toma Advanced Biomedical Assays S.p.A. (Busto Arsizio (VA), Italy) by standard cytogenetic techniques with QFQ banding using quinacrine mustard (haploid karyotype of 400-band level). Twentytwo metaphase spreads were analyzed. Clonal chromosomal abnormalities were described according to the International 
System for Human Cytogenetic Nomenclature (ISCN, 2009; Brothman et al., 2009).

\section{Propidium iodide staining for DNA ploidy analysis}

Trypsinized cell suspensions were centrifuged, washed three times with phosphate-buffered saline (PBS) and resuspended at $\mathrm{I} \times 10^{6} \mathrm{cells} / \mathrm{ml}$ in PBS. Cells were mixed with cold absolute ethanol and stored for $\mathrm{I} h$ at $4^{\circ} \mathrm{C}$. After centrifugation, cells were rinsed three times in PBS and the pellet was suspended in I $\mathrm{ml}$ of propidium iodide staining solution ( $3.8 \mathrm{mM}$ sodium citrate, $25 \mu \mathrm{g} /$ $\mathrm{ml} \mathrm{PI}, 10 \mu \mathrm{g} / \mathrm{ml}$ RNase A; Sigma-Aldrich Srl, Milano, Italy) and kept in the dark at $4^{\circ} \mathrm{C}$ for $3 \mathrm{~h}$ prior to flow cytometry analysis. Normal human lymphocytes were used as a diploid control.

\section{Flow cytometry analysis}

Samples were run on a COULTER EPICS XL flow cytometer (Beckman Coulter Srl, Cassina De Pecchi (MI), Italy) equipped with a single argon ion laser (emission wavelength of $488 \mathrm{~nm}$ ) and Expo 32 software. The red fluorescence of the propidium iodide-stained DNA was measured in the FL3 channel using a $620 \mathrm{~nm}$ BP filter. At least $\mathrm{I} \times 10^{4}$ cells/sample were analyzed and data were stored in list mode files. Samples were classified according to DNA index range as described by Bauer (1988).

\section{Array CGH analysis}

Array-based comparative genomic hybridization (array CGH) analysis was performed, as reported for karyotype analysis, by Toma Laboratories. The analysis was comparatively performed on DNA extracted from 3AB-OS and MG63 cells. A genome-wide BAC platform (the ConstitutionalChip 4.0, PerkinElmer LAS, Wallac, Turku, Finland) with an average resolution of $0.6 \mathrm{Mb}$ was used. Genomic DNA was extracted by the QIAamp DNA Mini Kit (Qiagen, Chatsworth, CA) following the manufacturer's instructions. Dye swap labeling, hybridization, and washing steps were carried out using the supplied kits and following the manufacturer's instructions. Hybridization spots were acquired by an Innoscan 700 Microarray Scanner (Innopsys, Carbonne, France) and analyzed with OneClick software $v$ 4.2.3, which summarizes results in graphical and tabular formats organized by chromosome location. Unbalanced aberration was measured by the average ratio values, which indicate losses for ratio values $<0.7$ and gains for ratio values $>$ I.3. The analytical method applied was the robust binary segmentation ( $P$-value: 0.001 ; min clones: 5 ; min Mbp: 0.I; threshold: 0.1 ). Molecular and conventional karyotypes were described according to the ISCN2009 guidelines (Brothman et al., 2009).

\section{Centrosome immunostaining, analysis of atypical mitotic figures, and nuclei number}

MG63, 3AB-OS cells, and HS68 (control fibroblasts) were grown in six-well plates for 2 days, washed with PBS, fixed with $3.7 \%$ formaldehyde and permeabilized with $0.1 \%$ Triton X-100 (Sigma-Aldrich Srl) in PBS.

All antibodies were diluted in PBS $+1 \%$ BSA $+0.05 \%$ NaN3 (Sigma-Aldrich). For centrosome analysis, asynchronously grown cells were incubated overnight at $4{ }^{\circ} \mathrm{C}$ with a rabbit monoclonal antibody against $\gamma$-tubulin (diluted I:2,000; Sigma-Aldrich Srl). The cells were then washed in PBS and exposed to Cy2-conjugated donkey anti-rabbit $\lg \mathrm{G}(\mathrm{H}+\mathrm{L})$ secondary antibody (diluted $\mathrm{I}: \mathrm{I00}$; Jackson ImmunoResearch Laboratories, West Grove, PA) for I h at room temperature.

For mitotic spindle analysis, cells were incubated overnight at $4 \mathrm{C}$ with a rabbit monoclonal antibody against $\gamma$-tubulin (diluted $\mathrm{I}: 2,000)$ and a mouse monoclonal antibody against $\beta$-tubulin (diluted I:100; Sigma-Aldrich Srl). The cells were then washed in $\mathrm{PBS}$ and exposed for $\mathrm{I} h$ at room temperature to $\mathrm{Cy2}$-conjugated donkey anti-rabbit $\lg \mathrm{G}(\mathrm{H}+\mathrm{L})$ secondary antibody and
Cy3-conjugated donkey anti-mouse $\lg \mathrm{G}(\mathrm{H}+\mathrm{L})$ secondary antibody (diluted I:I00; Jackson ImmunoResearch Laboratories).

Nuclei were visualized after staining with DAPI (4',6-diamidino2-phenylindole; Sigma-Aldrich Srl) at a concentration of $1 \mu \mathrm{g} / \mathrm{ml}$ in $\mathrm{PBS}$ at room temperature for $10 \mathrm{~min}$.

Samples were examined on a Leica DM IRB inverted microscope (Leica Microsystems Srl, Milano, Italy) equipped with epifluorescence optics and suitable filters for DAPI, FITC, and rhodamine detection; Images were photographed and captured by a computer-imaging system (Leica DC300F camera and Adobe Photoshop for image analysis).

The percentage of cells with abnormal centrosome number $(>2)$ was evaluated in 100 isolated (non-overlapping) cells. The percentage of multipolar mitotic cells $(\geq 3)$ was evaluated in 100 cells undergoing mitosis. The percentage of bi- and multinucleated cells was evaluated in I,000 isolated (non-overlapping) cells. Four independent experiments, each conducted in triplicate, were performed for centrosome, mitotic spindle, and nucleus analyses.

\section{Microarray analysis}

Microarray analysis was performed as previously described (Federico et al., 20I0). The analysis was comparatively performed on total RNA extracted from MG63 and $3 A B-O S$ cells following the manufacturer's protocol (Affymetrix, Santa Clara, CA). Hybridization to the UI33 Plus 2.0 (Genechip, Affymetrix), washing, and scanning were performed according to the manufacturer's protocol. Washing and staining were performed using the Affymetrix GeneChip Fluidic Station 450. Probe arrays were scanned using Affymetrix GeneChip Scanner 3000 G7. Statistical analysis was performed using the method of robust multiarray analysis (RMA) described by Irizarry et al. (2003). To identify differentially expressed genes, gene expression intensity was compared using a moderated $t$-test and a Bayes smoothing approach developed for a low number of replicates (Smyth, 2004). To correct for the effect of multiple testing, the false discovery rate was estimated from $P$ values derived from the moderated $t$-test statistics (Benjamini et al., 200 I). The analysis was performed using the affylmGUI graphical user interface for the limma microarray package (Wettenhall et al., 2006).

\section{KEGG and BioCarta analysis}

Differentially expressed genes were analyzed according to predefined pathways annotated by KEGG (Kyoto Encyclopedia of Genes and Genomes; http://www.genome.ad.jp/kegg; Kanehisa and Goto, 2000) and BioCarta (BioCarta Pathways [http:// www.biocarta.com/genes/allPathways.asp]) using the Gene Set Analysis Toolkit. To determine whether the proportion of the genes falling into each category (down- and up-regulated) was statistically significant, a hypergeometric test was applied (cutoff $P$-value of 0.01 ). It should be noted that, in general, one gene can participate in more than one KEGG or BioCarta pathway.

\section{miRNAs expression profiling using the $\operatorname{TaqMan}{ }^{\circledR}$ human} microRNA array

Total cellular RNA and miRNAs were isolated from MG63 and $3 A B-O S$ cells using the miRNeasy Mini Kit (Qiagen) and quantified using a 2100 Bioanalyzer (Agilent Technologies, Santa Clara, CA). Total RNA (600 ng) was reverse-transcribed using Megaplex ${ }^{\text {TM }}$ RT Primers Human Pool A (Applied Biosystems, Foster City, CA) according to the manufacturer's instructions. The cDNA obtained was loaded onto TaqMan ${ }^{\circledR}$ Human MicroRNA Array A (Applied Biosystems) according to the manufacturer's protocols, and then run on an ABI-PRISM 7900 HT Sequence Detection System (Applied Biosystems). Data were quantified using the SDS 2.I software and normalized using MammU6 as endogenous control. The $2^{-\Delta \Delta C_{t}}$ method was used to calculate the relative changes in gene expression (Livak and Schmittgen, 200I). 


\section{Predictive miRNAs for predictive target genes}

The predictive miRNA targets were determined by using five databases (TargetScan 5.I, MiRanda, PICTAR, miRbase, and DIANA-microT databases) and applying the following criteria: (i) the selected miRNAs must be predicted by at least two of the five databases employed; (ii) considering the levels of expression of both miRNAs and mRNA targets, for given $\mathrm{Xg}$, the analysis must select only those miRNAs satisfying:

$$
\frac{\left|X_{m}+X_{g}\right|}{\left|e_{g}\right|}<1
$$

where $|\cdot|$ is the absolute value function. Given that $\mathrm{eg}=\mathrm{Xg} / 2$, the above reads:

$$
\frac{\left|X_{m}+X_{g}\right|}{\left|X_{g}\right|}<\frac{1}{2}
$$

we denoted $X_{m}$ and $X_{g}$ as miRNAs and gene expression values, respectively.

The relationships between miRNA/mRNA expression profiles were determined by evaluating Pearson's correlation coefficient (r). This coefficient, for continuous (interval level) data, ranges from $-\mathrm{I}$ to $+\mathrm{I}$. A correlation $>0.8$ is generally described as strong, whereas a correlation $<0.5$ is described as weak.

\section{Quantitative real-time PCR}

Real-time PCR mixtures were prepared as previously described (Federico et al., 20I0). Quantitative real-time PCR (qPCR) was performed using the primers (Proligo, Milan, Italy) provided in Table I, and qPCR data were analyzed by SDS 2 . I software. Relative transcript levels were determined using the $2^{-\Delta \Delta C_{t}}$ method (Livak and Schmittgen, 200I) and normalized to GAPDH.

\section{Western blot analysis}

Cells were washed in PBS and incubated in ice-cold lysis buffer (RIPA buffer $50 \mu \mathrm{l} / 10^{6}$ cells) containing protease inhibitor cocktail (Sigma-Aldrich Srl) for 30 min and then sonicated three times for $10 \mathrm{sec}$. Equivalent amounts of proteins $(40 \mu \mathrm{g})$ were separated by SDS-polyacrylamide gel electrophoresis and transferred to a nitrocellulose membrane (Bio-Rad Laboratories Srl, Segrate (MI), Italy) for detection with primary antibodies against CCND2, GHR, HMGA2, IGF2, MEST (PegI), MSTN (GDF8; diluted I:300;

Santa Cruz Biotechnology, Santa Cruz, CA), and Lin28B (diluted I:I00; Abcam, Cambridge, UK) and the appropriate horseradish peroxidase-conjugated secondary antibodies. Immunoreactive signals were detected using enhanced chemiluminescence $(E C L)$ reagents (Bio-Rad). The correct protein loading was confirmed by stripping the immunoblot and reprobing with primary antibody for actin (diluted I:500; Sigma-Aldrich Srl). Quantification was performed using Quantity One software, and the data (relative density normalized to actin) were expressed as mean \pm SD of four experiments.

\section{Statistical analysis}

Data, represented as mean $\pm S D$, were analyzed using the twotailed Student's t-test.

\section{Results}

\section{Karyotyping 3AB-OS CSCs}

The human osteosarcoma cell line MG63, from which 3AB-OS CSCs were produced, has a complex karyotype with a chromosome number ranging from 61 to 66 (hypotriploid karyotype), with chromosome translocations and gains/losses in genomic sequences, accompanied by trisomies of numerous chromosomes, nullisomy of chromosome 9 and $18-19$ marker chromosomes (Lim et al., 2004).

In this study, we assessed the ploidy of $3 A B-O S$ cells by QFQ banding chromosome analysis. The analysis of 22 metaphase spreads showed that the $3 \mathrm{AB}-\mathrm{OS}$ karyotype is a hypertriploid composite ( $\mathrm{CP})$, with great heterogeneity and a modal number of chromosomes ranging from $7 \mathrm{I}$ to 82 . The main and recurrent chromosome abnormalities were: trisomies for chromosomes I, 4, II, I6, I8, and 20; monosomy for chromosome 19; nullisomy for chromosomes 9 and $\mathrm{Y}$; a number of supernumerary marker chromosomes ranging from 31 to 35 ; derivative of chromosome 9; and other chromosome structural abnormalities. The ISCN karyotype was defined as follows: $7 \mathrm{I}-$ $82, X,-Y,+I,+4,-9,-9, \operatorname{der}(9),+11,+16,+18,-19,+20$, $+31-35 \mathrm{mar}[\mathrm{cp} 22]$. Figure IA shows an aneuploid karyotype with 78 chromosomes and the following characteristics: trisomies of chromosomes I, 4, II, I6, 18, and 20; monosomies of chromosomes 3 and 22; nullisomies of chromosomes 9, 19, and $Y$; derivative of chromosome $9\left(\operatorname{mar}^{*}\right)$; and 32 unidentifiable marker chromosomes. In Figure IB, flow-cytometric analysis shows a DNA index of I.70 (triploid cells) for MG63 cells and of 2.I (tetraploid cells) for 3AB-OS cells.

\section{Array CGH analysis}

To detect unbalanced chromosomal changes in 3AB-OS cells, we performed array $\mathrm{CGH}$ analysis in comparison with MG63 cells. Figure IC describes the profiles of individual chromosomes. Table 2 presents the CNV type (loss/gain), the involved chromosome (Chr), the map positions (start/end bp), the chromosomal band (start/end chr band), and the size of chromosomal aberration (Mb), according to the International Human Genome Consortium (build36; March 2006; hgl8). Overall, as indicated in both Figure IC and Table 2, most of the chromosomes had aberrations ranging from 0.9 to $116 \mathrm{Mb}$. In particular, we identified 49 CNVs (22 gains and 27 losses) distributed among most of the chromosomes, with homozygous losses detected in chromosomes 4, 6, 8, and 9.

\section{Centrosome, multipolar spindles, and} nuclei number analyses

During mitosis, centrosomes direct the formation of bipolar mitotic spindles that ensure equal segregation of chromosomes between daughter cells. Loss of centrosome homeostasis induces centrosome amplification, aberrant mitosis, and

\begin{tabular}{|c|c|c|}
\hline Gene & Forward primer $5^{\prime}-3^{\prime}$ & Reverse primer $5^{\prime}-3^{\prime}$ \\
\hline $\begin{array}{l}\text { CCND2 } \\
\text { GHR } \\
\text { HMGA2 } \\
\text { IGF2 } \\
\text { LIN28B } \\
\text { MEST/PEGI } \\
\text { MSTN } \\
\text { GAPDH }\end{array}$ & $\begin{array}{l}\text { TCACCAACACAGACGTGGA } \\
\text { CCAGTTTCCATGGTTCTTAATTAT } \\
\text { CGAAAGGTGCTGGGCAGCTCCGG } \\
\text { CCTCCAGTTCGTCTGTGGG } \\
\text { CCTGTTTAGGAAGTGAAAGAAGAC } \\
\text { CCTGTAGGCAAGGTCTTACCTG } \\
\text { TGGTCATGATCTTGCTGTAACCTT } \\
\text { TTCGACAGTCAGCCGCATCTTCTT }\end{array}$ & $\begin{array}{l}\text { TGTAGGGGTGCTGGCTTG } \\
\text { TTCCTTTAATCTTTGGAACTGG } \\
\text { CCATTTCCTAGGTCTGCCTCTTG } \\
\text { CACGTCCCTCTCGGACTTG } \\
\text { CACTTCTTTGGCTGAGGAGGTAG } \\
\text { GAAGACTTCCATGAGTGAAGGGC } \\
\text { TGTCTGTTACCTTGACCTCTAAAA } \\
\text { GCCCAATACGACCAAATCCGTTGA }\end{array}$ \\
\hline
\end{tabular}

TABLE I. Primers used for real-time RT-PCR analysis 
A

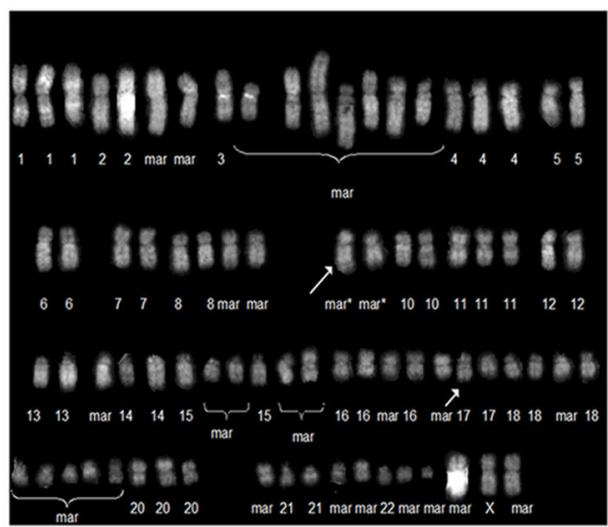

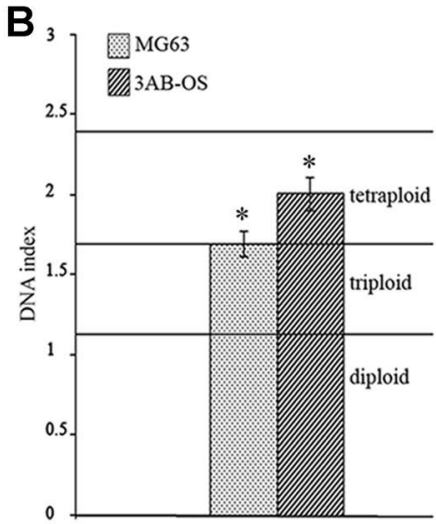

C

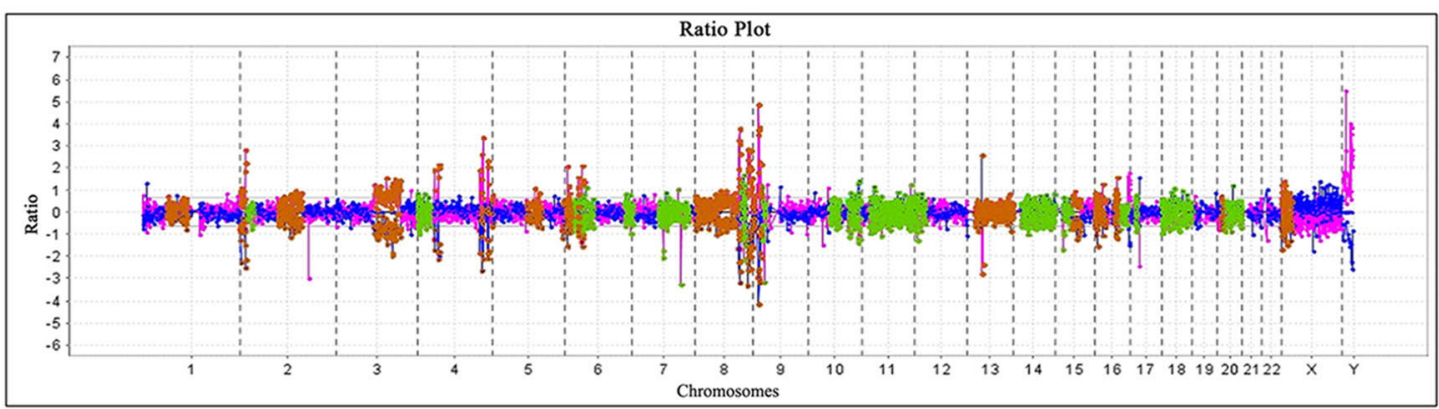

Fig. I. Cytogenetics and DNA ploidy. A: Typical metaphase analysis of 3AB-OS cells. B: Ploidy pattern in human osteosarcoma MG63 and 3 ABOS cells. Normal human lymphocytes were used as a diploid control. The data represent the mean with standard deviation $(n=4) .{ }^{*} p<0.01 ; t$-test. C: Whole genome $\mathrm{aCGH}$ profiles of $3 \mathrm{AB}-\mathrm{OS}$ cells. $X$-axis represents individual chromosomes and $Y$-axis represents the signal intensity in log 2 ratio (3AB-OS/MG63). Green dots represent the probes above ratio zero and red dots those below ratio zero. The analytical method applied was the robust binary segmentation ( $P$-value: 0.001 ; $\min$ clones: 5 ; $\min$ Mbp: 0.1 ; threshold: 0.1 ).

altered chromosomes (Fukasawa, 2005). In

Figure 2A, fluorescence microscopy (a) shows the centrosomes, while diagram (b) indicates the percentage of cells with abnormal centrosome number $(>2)$. Only a few supernumerary centrosomes (3.7\%) were found in HS68 cells, while the percentage of these chromosomes was $16.3 \%$ in MG63 cells and $32.5 \%$ in $3 A B-O S$ cells. Figure $2 \mathrm{Ba}$,b shows that there were no atypical mitotic spindles in HS68, but that $20.4 \%$ of MG63 cells and $32.8 \%$ of $3 \mathrm{AB}-\mathrm{OS}$ cells exhibited multipolar mitotic spindles. Figure $2 \mathrm{C}$ shows that both MG63 and $3 \mathrm{AB}-\mathrm{OS}$ cells exhibited bi-and multinucleation, in contrast to HS68 cells with no abnormal nuclei. In $3 \mathrm{AB}-\mathrm{OS}$ cells, the percentage of binucleated (BN, 3.5\%) and multinucleated (MN, 6.9\%) cells was much greater than in MG63 cells (BN, I.3\%; MN, I.0\%). In addition, $3 A B-O S$ cells exhibited numerous multinucleated giant cells (c), which were not found in MG63 cells.

Figure $2 \mathrm{C}$ also shows, in both MG63 and 3AB-OS cells, the presence of micronuclei $(\mathrm{mn})$, which were more prevalent in 3AB-OS cells (data not shown).

\section{Transcriptome analysis of 3AB-OS cancer stem cells}

Affymetrix microarray analysis was performed to identify differentially expressed genes (DEGs) in 3AB-OS cells with respect to MG63 cells. To represent the full list of DEGs (Supplementary Table I), we generated a heat map by hierarchical clustering, as implemented in GeneSpring GX (Fig. 3A), which grouped 3,5 I 2 DEGs of which I,632 were upregulated (fold change $\geq I$ ) and I,880 down-regulated (fold change $\leq-\mathrm{I})$. We applied to the 3,5I 2 DEGs the bioinformatic resources KEGG and BioCarta. KEGG analysis classified 518 genes of which 335 were from the down-regulated list and 183 from the up-regulated list, while BioCarta analysis classified I 30 genes of which 73 were from the down-regulated list and 57 from the up-regulated list. A full list of the identified pathways, ranked by a hypergeometric test $P$-value (up-/down-regulated pathways), is shown in Figure $3 \mathrm{~B}$.

To select the pathways correlated with the most important processes that characterize carcinogenesis and stemness, we integrated the KEGG and BioCarta data. Figure 4 presents the 162 up-/down-regulated genes involved in the following pathways: WNT signaling ( $3 \mathrm{I}$ genes; $P$-value $=4$.7IE-04); Notch signaling (seven genes; $P$-value $=6.76 \mathrm{E}-03$ ); Hedgehog signaling (eight genes; $P$-value $=1.90 \mathrm{E}-03$ ); $A B C$ transporters general (I I genes; $P$-value $=3.57 \mathrm{E}-03)$; MAPK signaling (47 genes; $P$-value $=2.16 \mathrm{E}-03)$; cell cycle regulators ( 14 genes; $P$ value $=3.72 \mathrm{E}-03)$; apoptosis $(24$ genes; $P$-value $=3.88 \mathrm{E}-05)$; ECM-receptor interaction and cell communication ( 36 genes; $P$-value $=5.52 \mathrm{E}-05$ ); and cell adhesion molecules ( 17 genes; $P$-value $=2.95 \mathrm{E}-03)$. Figure 4 also illustrates 34 genes either highly up-regulated ( 14 genes, fold change $\geq 6.3$; $P$-value $=$ $2.05 \mathrm{E}-05)$ or strongly down-regulated ( 20 genes, fold change $\leq-6.3 ; P$-value $=2.48 \mathrm{E}-05)$, most of which were not attributable to specific pathways.

\section{MicroRNA expression in MG63 and in 3AB-OS cells}

Here, we analyzed the miRNAs present in MG63 and 3AB-OS cells. We identified 189 miRNAs of which 152 differentially expressed in the two cell lines (Fig. 5A) and 37 termed 
TABLE 2. Array CGH analysis of $3 A B-O S$ cells DNA (testing) compared with MG63 cells DNA (reference)

\begin{tabular}{|c|c|c|c|c|c|c|}
\hline $\begin{array}{l}\text { CNV } \\
\text { type }\end{array}$ & $\mathrm{Chr}$ & Start (bp) & End (bp) & $\begin{array}{c}\text { Start } \\
\text { (chr band) }\end{array}$ & $\begin{array}{c}\text { End } \\
\text { (chr band) }\end{array}$ & $\begin{array}{l}\text { Size } \\
(\mathrm{Mb})\end{array}$ \\
\hline Loss & I & $60,900,000$ & $84,900,000$ & $1 \mathrm{p} 31.3$ & I p22.3 & 24 \\
\hline oss & i & $95,800,000$ & $113,300,000$ & |p2|.3 & $|p| 3.2$ & \\
\hline Loss & 2 & 100,000 & $13,300,000$ & $2 p 25.3$ & $2 p 24.3$ & 13 \\
\hline Gain & 2 & $17,700,000$ & $32,400,002$ & $2 p 24.2$ & $2 p 22.3$ & \\
\hline Loss & 2 & $94,900,000$ & $156,900,000$ & $2 q 11.1$ & $2 q 24.1$ & \\
\hline Loss & 3 & $95,500,000$ & $162,100,000$ & $3 q 11.2$ & $3 q 26.1$ & \\
\hline Gain & 4 & 100,000 & $34,500,000$ & $4 p 16.3$ & $4 p 15.1$ & \\
\hline 2$\rangle$ & 4 & $42,468,752$ & $43,427,148$ & $4 \mathrm{p} 13$ & $4 p / 3$ & \\
\hline $2 \times$ Loss & 4 & $52,627,772$ & $54,544,572$ & $4 q 12$ & $4 q 12$ & \\
\hline $2 \times L$ & 4 & $158,700,000$ & $165,400,000$ & $4 q 32.1$ & $4 q 32.3$ & \\
\hline $2 \times$ Loss & 4 & $188,600,000$ & $190,600,000$ & $4 q 35.2$ & $4 q 35.2$ & \\
\hline Loss & 4 & $176,069,488$ & $|80,478| 1 \mid 2$, & $4 q^{3}$ & & \\
\hline Loss & 5 & 000 & 122 & $5 q$ & & \\
\hline Los & 5 & $176,800,000$ & 178 & $5 q^{3}$ & $5 q 35.3$ & \\
\hline Lo & 6 & 000 & & $6 p^{2}$ & & \\
\hline $\mathrm{Ga}$ & 6 & 15,6 & 32, & $6 p^{2}$ & $6 \mathrm{p} 2$ & \\
\hline 2$\rangle$ & 6 & & & & & \\
\hline & 6 & & 44 & & & \\
\hline $\mathrm{Ga}$ & 6 & 45 & 47, & & 3 & \\
\hline & 6 & 000 & 71,6 & & & \\
\hline $\mathrm{Ga}$ & 6 & $152, \mid$ & 170,6 & $6 q^{2}$ & $6 c$ & \\
\hline Loss & 6 & 044 & & & $6 \mathrm{p}$ & \\
\hline $\mathrm{Ga}$ & 7 & 004 & 143 & $7 q 1$ & $7 c$ & \\
\hline & 8 & & & & & 10 \\
\hline os & 8 & 109,6 & bo & $8 q 2$ & $8 \mathrm{q} ?$ & \\
\hline & 8 & 116 & & & & \\
\hline & 8 & 120 & 126 & $8 q 2$ & $8 \mathrm{q} 2$ & \\
\hline $2 \times$ Loss & 8 & 13 & 144 & & & \\
\hline & 9 & 0 & & 3 & $9 \mathrm{p} 24.2$ & \\
\hline & 9 & & & & & \\
\hline Los & 9 & & 0 & $9 \mathrm{p} 2$ & $9 p^{2}$ & \\
\hline & 0 & & & & & \\
\hline $\mathrm{Ga}$ & 10 & 0 & 78,7 & $10 q \mid 1.23$ & $10 \mathrm{q} 22.3$ & \\
\hline & 10 & & & & & \\
\hline $\mathrm{Ga}$ & 11 & & 134 & .1 & IIC & \\
\hline & in & & & & & \\
\hline Los & 13 & 18,50 & 114 & $|3 q| 2.1 \mid$ & $13 q 34$ & \\
\hline $\mathrm{Ga}$ & 14 & & & & & \\
\hline $\mathrm{Ga}$ & 14 & & 106 & $14 q 23.3$ & $14 q 32.33$ & \\
\hline Gai & 15 & & & & & \\
\hline Los & 15 & & & $15 q 21.1$ & $15 q 2$ & \\
\hline Lo & 16 & & & 4 & $16 \mathrm{p}$ & \\
\hline Lo & 16 & $50,000, c$ & 58,3 & $16 q 12.1$ & $16 q 21$ & \\
\hline Gai & 16 & & 83,6 & 160 & 16q24.1 & \\
\hline $\mathrm{Ga}$ & 17 & 0 & 17,0 & $17 p 12$ & $|7 p| 1.2$ & \\
\hline Gair & 18 & 200,000 & & $|8 p| \mid .32$ & $18 q 23$ & \\
\hline Los & 20 & 7,70 & 10,0 & $20 \mathrm{p} / 2.3$ & $20 \mathrm{p} \mid 2.2$ & \\
\hline $\mathrm{Ga}$ & 20 & $14,500, \mathrm{C}$ & & $20 \mathrm{p} \mid 2.1$ & $20 \mathrm{q} / 3.33$ & \\
\hline Loss & $x$ & 300,000 & $26,900,000$ & Xp22.33 & Xp21.3 & \\
\hline
\end{tabular}

"3AB-OS-only" expressed only in 3AB-OS cells (Table 3 ). Overall, $3 A B-O S$ cells showed, with respect to MG63 cells, 54 up-regulated miRNAs with relative quantification $(R Q) \geq 1,98$ down-regulated miRNAs with $R Q \leq-I$, and 37 " $3 A B-O S$ only" miRNAs, for which RQ could not be calculated as they were not measurable in MG63 cells.

To determine which of the 189 identified miRNAs may be predictively involved in the control of the 196 selected genes, we performed an analysis employing five integrated databases (Supplementary Table 2). Based on this analysis, we selected 46 miRNAs, which included 9 up-regulated, 10 "3AB-OS-only," and 27 down-regulated (Table 4). The results of this integrated analysis also permitted the evaluation of the number and percentage of genes present in predictably functional pathways (Table 5). The results show that, excluding Notch and Hedgehog signaling, and $A B C$ transporter general pathways, all other pathways have a percentage of targeted genes $>30 \%$, suggesting that those genes could be strongly controlled by the miRNAs identified. Integration of miRNAs and anticorrelated genes yielded evidence, by Pearson's correlation coefficient analysis $(r=-0.96)$, of a strong inverse linear correlation (Fig. 5B). As reported in Supplementary Table 3, the 46 miRNAs appeared to regulate the expression of 78 of the 196 selected genes, and 23 of them seemed to be under the control of " $3 A B$ OS-only" miRNAs. Supplementary Table 3 also shows that, among the down-regulated miRNAs, those with the most predictive target genes are the miRNAs families let 7/98 (I5 target genes) and 29a,b,c (7 target genes). Thus, based on these analyses, we selected from the list presented in Supplementary Table 3 the members of the miRNA families with their most strongly up-regulated predictive genes. Table 6 lists the members of the let-7/98 family (mean fold change -4.9) that appear to be anti-correlated with HMGA2 (high mobility group AT-hook 2; fold change +6.7), Lin28B (Lin-28 homolog B; fold change +6.9), CCND2 (cyclin D2; fold change +8.I), MEST (mesoderm-specific transcript; fold change +6.3 ) and GHR (growth hormone receptor; fold change +5.0 ) genes; this table also gives the members of the miR-29a,b,c family (mean fold change -4.6 ) that appear to be anti-correlated with the MSTN (myostatin; fold change +8.6), CCND2 and MEST genes. Even though our analysis indicated that IGF2 (insulin-like growth factor 2; fold change +7.I) did not appear to be under the control of identified miRNAs, it is also enclosed in Supplementary Table I, as it could be strongly influenced by Lin28B (Lu et al., 2009).

To test whether expression differences evaluated by microarray analysis were reproducible for this subset of genes, we performed quantitative real-time PCR (q-PCR) with independently collected RNA samples. The results (Fig. 5C) were in agreement with the microarray analysis. To evaluate whether these mRNAs were translated, we then measured the expression levels of these genes by Western blot analysis (Fig. 5D), showing that the levels of the corresponding proteins (Fig. 5E) were higher in 3AB-OS than in MG63 cells (fold change ranging from $\mathrm{I} .4$ to 2.8 ).

\section{Discussion}

Most highly malignant cells have an abnormal number of chromosomes characterized by changes in structure, with their karyotypic complexity being associated with aggressive clinical behavior and poor prognosis (Roschke and Kirsch, 2010). Since tumors with a poor outcome have been associated with CSC presence, the number of papers describing CSCs has markedly increased (McCubrey et al., 20I2). Nevertheless, until now, genetic and molecular characterization of CSCs has been little explored.

Previously, we have reported for the first time the isolation of a human osteosarcoma cancer stem cell line (3AB-OS). Here, we characterized the $3 \mathrm{AB}-\mathrm{OS}$ cell line at genetic and molecular level, and to our knowledge, this is the first CSC line to be characterized.

We found that $3 \mathrm{AB}-\mathrm{OS}$ cells have a significant chromosomal complexity and a large number of molecular abnormalities, which are characteristic of the most aggressive human cancers. Compared to parental MG63 cells, which have a hypotriploid karyotype and chromosome number ranging from 61 to 66 , $3 \mathrm{AB}-\mathrm{OS}$ cells had a hypertriploid karyotype and chromosome number ranging from $7 \mathrm{I}$ to 82 . 3AB-OS cells also showed monosomies, trisomies and nullisomies, together with 32 unidentifiable marker chromosomes, and they exhibited 49 $\mathrm{CNVs}$ (gains/losses), spanning almost all the chromosomes. Remarkably, the abnormalities evidenced in 3AB-OS cells appear to be strongly congruent with abnormalities described in the literature in a large number of pediatric and adult osteosarcomas (Bridge et al., 1997; Batanian et al., 2002; Niini et al., 20 I I), which have shown a karyotype ranging from haploid to near hexaploid, with structural abnormalities involving the chromosomal regions IpII-13, 4q27-33, 6p2325, 6ql6-25, 7ql|-36, IIp|0-15, I|q23, and I7p|I.2-13. Moreover, $3 \mathrm{AB}-\mathrm{OS}$ cells showed losses/gains in agreement 
A

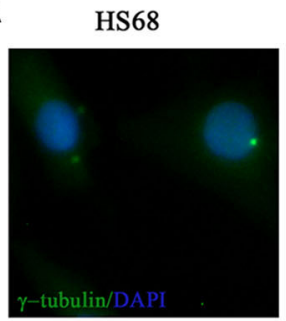

a

B
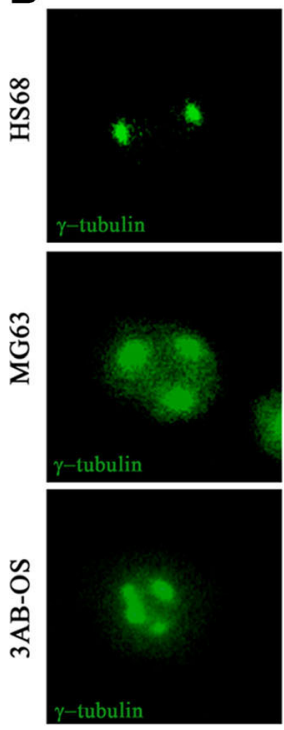

a

C
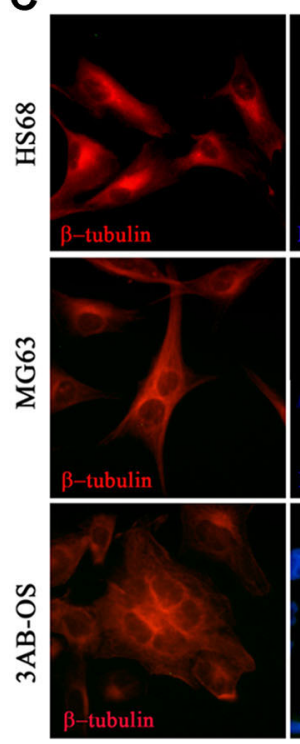

MG63

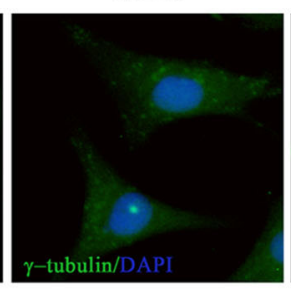

$\gamma$-tubulin/DAPI $\quad \gamma$-tubulin/DAPI
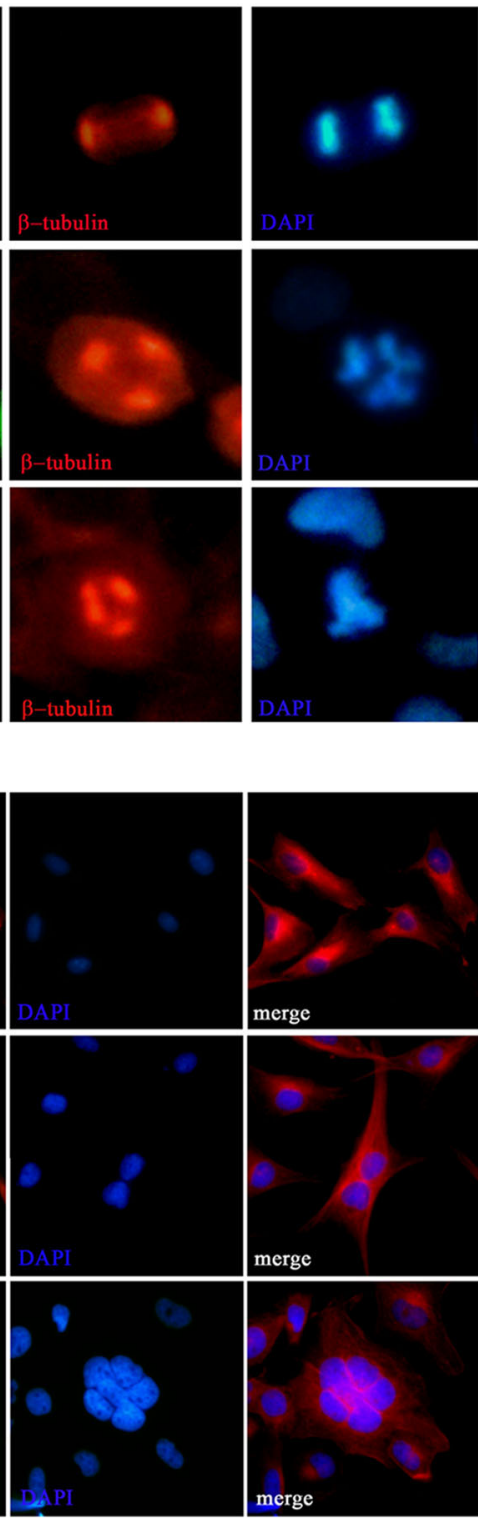

merge

merge
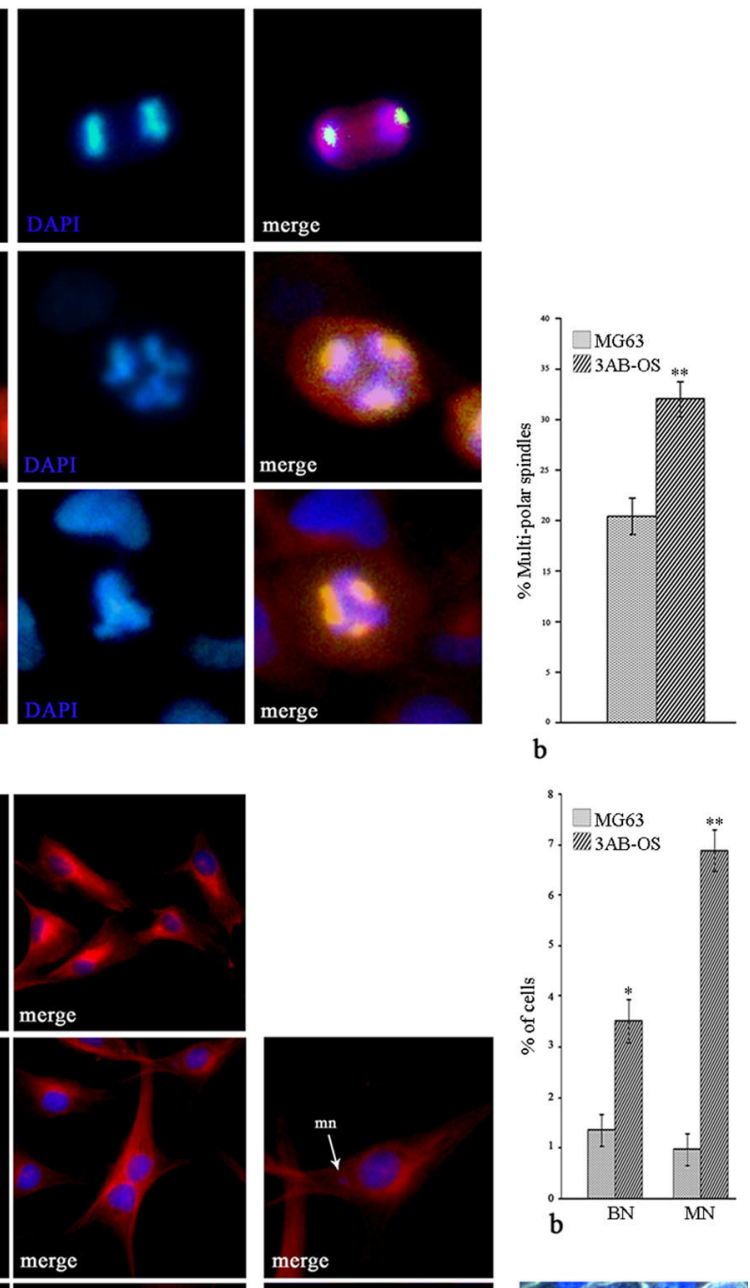

b
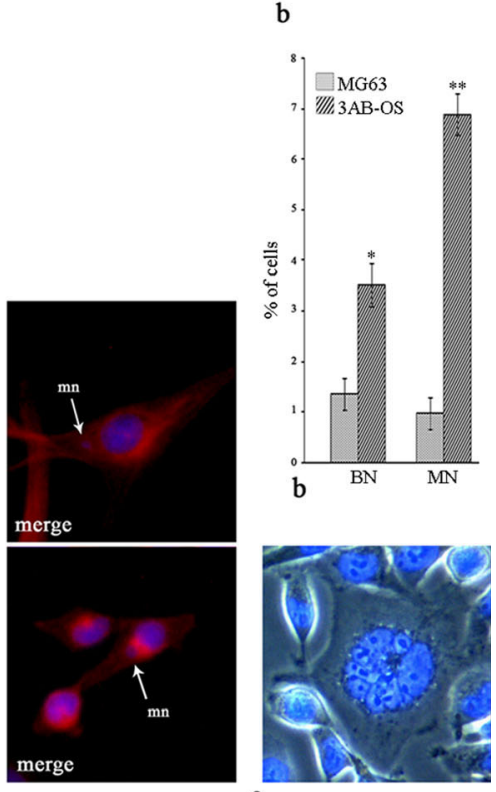

b

Fig. 2. Immunofluorescence microscopy analysis of centrosomes, mitotic spindles, and nuclei in HS68 (control fibroblasts), MG63, and 3AB-OS cells. Aa: Centrosomes were detected by the presence of $\gamma$-tubulin (green) and nuclei by DAPI (blue). Ab: Graph summarizing centrosome aberration frequency. Ba: Multipolar spindles were detected by the presence of $\gamma$-tubulin (green) and $\beta$-tubulin (red); nuclei by DAPI (blue). Bb: Graph summarizing aberrant spindle percentages $(\geq 3)$. Ca: Binucleated $(B N)$ and multinucleated $(M N)$ cells detected by the presence of $\beta$-tubulin (red) and DAPI (blue). Arrows indicate micronuclei $(\mathrm{mn})$. Cb: Graph summarizing the percentage of binucleate and multinucleate cells. Cc: multinucleated giant cell detected by DAPI (blue). The data represent the mean with standard deviation $(n=4) .{ }^{*} P<0.05$ and ${ }^{* *} P<0.005$; t-test. Original magnification, $400 \times$. 
A

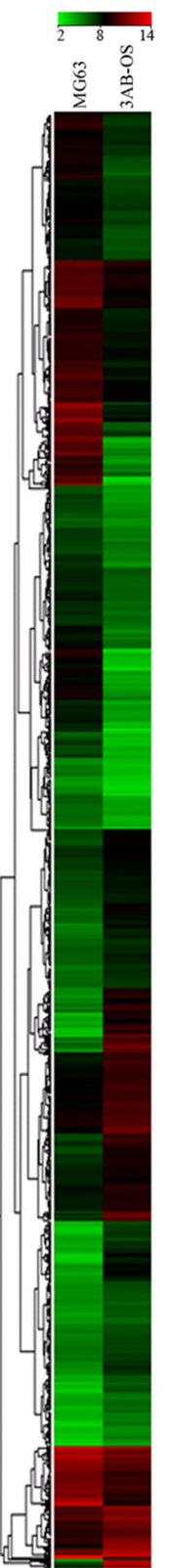

B

$\frac{\text { KEGG enrichment }}{\mathrm{n}^{\circ} \text { genes }}$

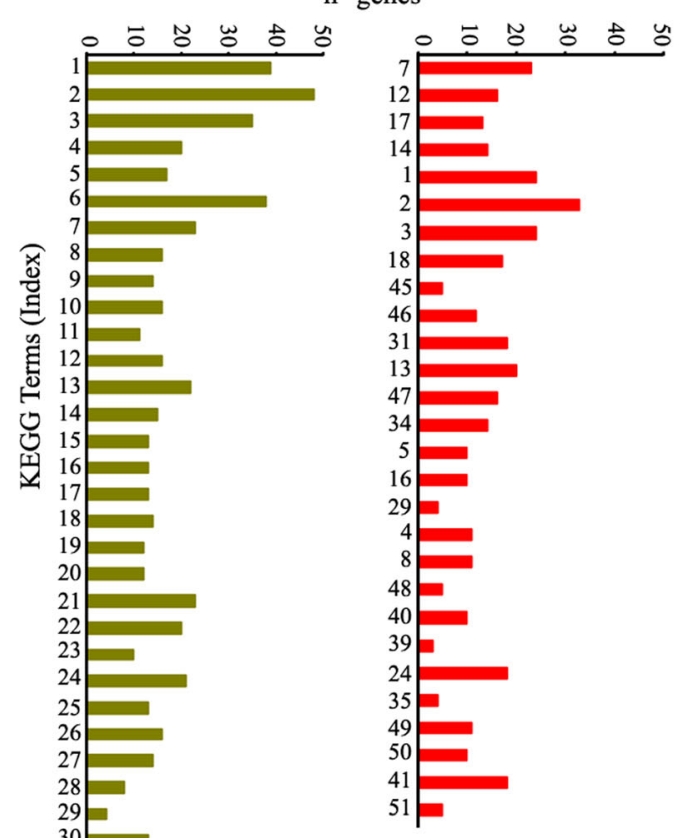

\section{Biocarta enrichment}

$\mathrm{n}^{\circ}$ genes

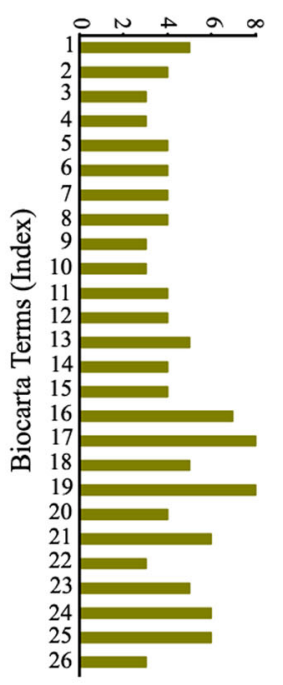

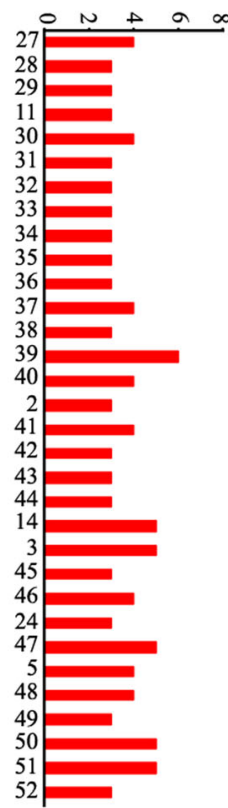

Fig. 3. Transcriptome analysis. A: Hierarchical clustering analysis of the expression data of MG63 and 3 AB-OS cell lines (cut-off $P$-value of $0.00 \mathrm{I}$ ). Each row represents a separate element on the microarray, and each column represents a cell line. In the heat map, the log scale of absolute expression values of both cell lines are represented by colors: green squares represent low-expressed genes, red squares represent high-expressed genes. B: Enrichment analysis for KEGG and BioCarta pathways. The bar chart shows the number of genes in the canonical KEGG or BioCarta pathways separately for down-regulated (green) and up-regulated (red) transcripts. For an over-represented KEGG or BioCarta pathway, a cut-off $P$-value of 0.01 was selected. Indices for KEGG and BioCarta terms are reported in Supplementary Figure I.

with those seen in osteosarcoma patients (Bridge et al., 1997; Batanian et al., 2002; Niini et al., 20I I), such as losses at chromosome arms 8p, 9p, 16p, 3q, 13q, and gains at chromosome arms 6p, 8q, 12p, 14q, 17p, and 20q.

It is known that karyotypic complexity is reflected in aneuploidy (chromosomal instability), which is believed to be a driving force for tumorigenesis (Roschke and Kirsch, 2010). Even if the origin of chromosomal instability is not clear, defects in both centrosome duplication and mitotic spindle checkpoint can be considered early features in tumor initiation and progression (Chan, 20I I). Our results show that both MG63 and $3 \mathrm{AB}-\mathrm{OS}$ cells have abnormal centrosome number, multipolar spindles, and bi- and multinucleation. In $3 A B-O S$ cells, these abnormalities appeared to be much higher than in MG63 cells, and they included a number of giant multinucleated cells, not evidenced in MG63 cells. Highly aneuploid cells have varied activation of pro-proliferative pathways with dysfunctions in cyclins, pRb, and E2F family transcription 

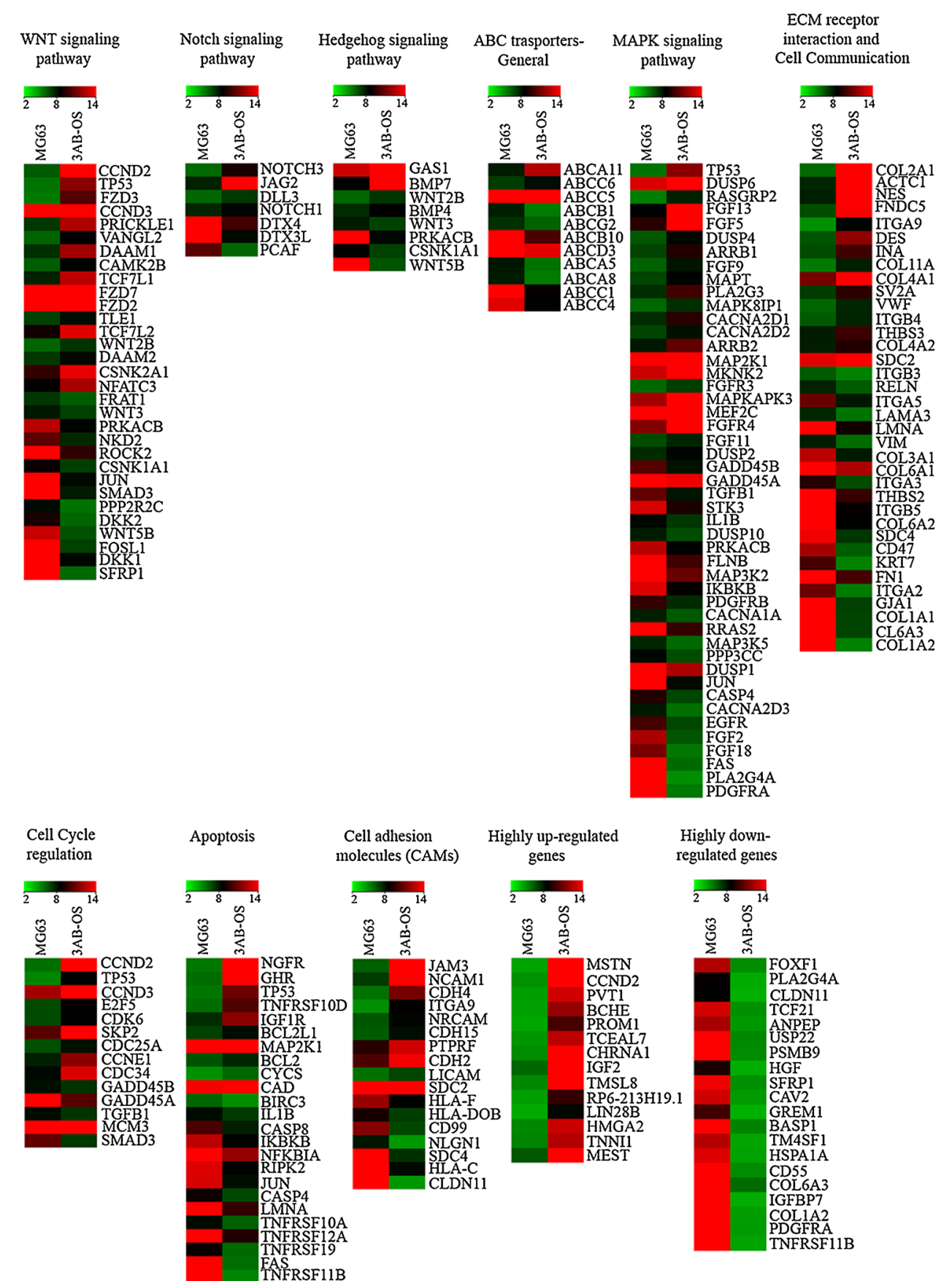

Fig. 4. Hierarchical clusterings related to pathways identified by the integrated analyses using KEGG and BioCarta databases. Representation of rows and columns is the same as reported in Figure 3. Also indicated are highly up-/down-regulated genes, most of which cannot be attributed to specific pathways.

factors, which could be crucial in centrosome amplification and chromosome instability (Mayhew et al., 2007). Similar dysfunctions have also been reported in osteosarcoma patients, where array $\mathrm{CGH}$ revealed frequent alterations of GI/S checkpoint genes (Niini et al., 20I I). We have previously shown (De Blasio et al., 2005) that, with respect to MG63 cells, 3ABOS cells express much higher levels of hyperphosphorylated $\mathrm{pRb}$, known to influence the timing of GI/S, and that this was accompanied by substantial increases in the levels of molecular partners contributing to GI/S and G2/M transition (Di Fiore et al., 2009). Now, we suggest a link between the altered gene expressions previously reported in $3 A B-O S$ cells and the centrosome amplification and aneuploidy described here.

We report here the gene expression profile of $3 A B-O S$ cells in comparison with MG63 cells and, employing KEGG and BioCarta analysis, we selected 196 up-/down-regulated genes spanning important regulatory pathways involved in tumorigenesis and stemness (WNT, Notch and Hedgehog signaling; $A B C$ transporters in general; MAPK signaling; cell cycle regulators; apoptosis; ECM-receptor interaction and cell 
communication; cell adhesion molecules), most of which have been reported in osteosarcoma patients (Cleton-Jansen et al., 2009).

It is known that miRNAs may act as oncogenes or tumor suppressor genes (lorio and Croce, 2009), and thus, they constitute a large gene regulatory network that can modulate proliferation, cancer, and stemness. This evidence raises the

A

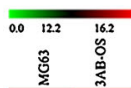

B

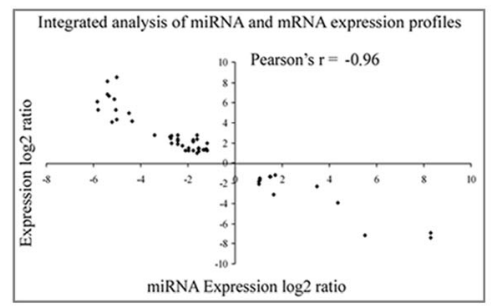

$\mathbf{C}_{14}$
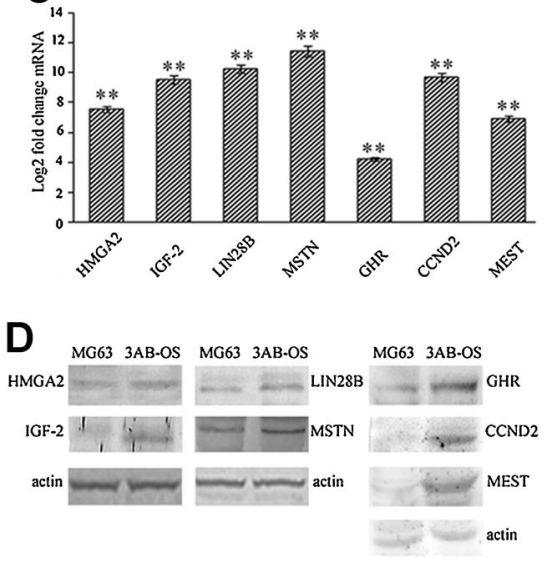

$E_{3,3}$

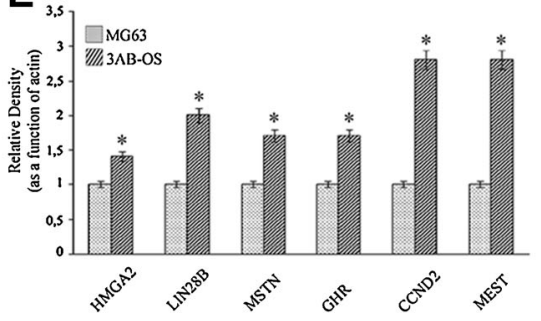

TABLE 3. "3AB-OS-only" miRNAs

hsa-miR-133a

hsa-miR-50I-3p

hsa-miR-654-5p

hsa-miR-493

hsa-miR-129-3p

hsa-miR-299-5p

hsa-miR-409-5p

hsa-miR-499-5p

hsa-miR-I

hsa-miR-5 I9a

hsa-miR-375

hsa-miR-188-3p

hsa-miR-I46b-3p

hsa-miR-54I

hsa-miR-I22

hsa-miR-517a

hsa-miR-338-3p

hsa-miR-369-5p

hsa-miR-519d

hsa-miR-49I-3p

hsa-miR-329

hsa-miR-654-3p

hsa-miR-429

hsa-miR-127-5p

hsa-miR-548b-5p

hsa-miR-4I 2

hsa-miR-506

hsa-miR-380

hsa-miR-5I7c

hsa-miR-376b

hsa-miR-5I I

hsa-miR-367

hsa-miR-302c

hsa-miR-369-3p

hsa-miR-89 Ia

hsa-miR-I36

hsa-miR-299-3p

intriguing idea to modulate microRNA expression as a possible therapeutic approach to cancer. In this study, we demonstrated the overexpression/underexpression of 189 miRNAs, of which 152 differentially expressed in 3AB-OS and MG63 cells and where 37 expressed in $3 A B-O S$ cells only. We submitted the selected genes to a predictive integrated analysis using five databases, and we selected 46 miRNAs with their predicted gene targets involved in pathways including apoptosis, cell cycle, Wnt, and MAPK. Interestingly, among these miRNAs, a large number of both up-regulated (miR-329, miR-335, miR-376a, miR-382, miR-409-5p, miR-127-3p, miR-376a, miR-376c, miR493, miR-495, miR-654-3p, miR-299-5p, miR-4l0, and miR223) and down-regulated (miR-I0b, miR-195, let-7g, miR-16-2, miR-5I9d, miR-26b, miR-16, and miR-29b) coincide with those identified in osteosarcoma patients (Maire et al., 20 I I; Jones et al., 20I2). Thus, studying 3AB-OS CSCs will permit the identification of new molecular pathways that could be

Fig. 5. miRNAs, q-real-time PCR, Western blot analyses, and miRNAs/antiregulated genes. A: Clustering of 152 differentially expressed miRNAs. Each row represents a separate element on the array, and each column represents a cell line. The scale (0.0-16.2) indicates the $\Delta C_{t}$ values represented by colors. Green squares represent up-regulation, and red squares represent down-regulation. $B$ : Integrated analysis of miRNA and mRNA expression profiles. $X$ axis (independent variable) represents the miRNA expression signal intensity ratio (3AB-OS/MG63) in $\log _{2}$ scale and $Y$-axis (dependent variable) represents the $m R N A$ expression signal intensity ratio (3AB-OS/MG63) in $\log _{2}$ scale. Pearson's $r$-value indicates the correlation coefficient. C: qPCR with independently collected mRNA samples. Relative transcript levels were determined using the $2^{-\Delta \Delta C_{t}}$ method and normalized to GAPDH. The data represent the mean with standard deviation $(n=4){ }^{* *} P<0.00 I$; $t$-test. D: Western blot analysis. E: Quantification of protein bands by densitometric analysis. The data (relative density normalized to actin) represent the mean with standard deviation $(n=4) .{ }^{*} P<0.05$; $t$-test. 
TABLE 4. miRNAS involved in the regulation of the selected pathways

\begin{tabular}{|c|c|}
\hline $\begin{array}{l}\text { Differential miRNA expression } \\
\text { in } 3 \mathrm{AB}-\mathrm{OS} \text { cells and MG63 cells }\end{array}$ & $\begin{array}{l}\text { miRNAs } \\
\text { number }\end{array}$ \\
\hline $\begin{array}{l}\text { Up-regulated } \\
\text { hsa-miR-200c; hsa-miR-32; hsa-miR-149; } \\
\text { hsa-miR-I 30a; hsa-miR-I35a; hsa-miR-I38; } \\
\text { hsa-miR-495; hsa-miR-I33b; hsa-miR-223a. }\end{array}$ & 9 \\
\hline $\begin{array}{l}\text { 3AB-OS-only } \\
\text { hsa-miR-429; hsa-miR-506; hsa-miR-302c; } \\
\text { hsa-miR-I; hsa-miR-367; hsa-miR-49I-3p; } \\
\text { hsa-miR-I 33a; hsa-miR-299-5p; } \\
\text { hsa-miR-299-3p; hsa-miR-5 I 9a. }\end{array}$ & 10 \\
\hline $\begin{array}{l}\text { Down-regulated } \\
\text { hsa-let-7c; hsa-let-7e; hsa-let-7a; } \\
\text { hsa-let-7g; hsa-let-7b; hsa-let-7f; } \\
\text { hsa-let-7d; hsa-miR-98; hsa-miR-195; } \\
\text { hsa-miR-182; hsa-miR-96; hsa-miR-15a; } \\
\text { hsa-miR-15b; hsa-miR-29a; hsa-miR-29b; } \\
\text { hsa-miR-29c; hsa-miR-186; hsa-miR-I52; } \\
\text { hsa-miR-148a; hsa-miR-21; hsa-miR-30b; } \\
\text { hsa-miR-186; hsa-miR-I83; hsa-miR-199a-3p; } \\
\text { hsa-miR-I53; hsa-miR-320; hsa-miR-34a. }\end{array}$ & 27 \\
\hline
\end{tabular}

TABLE 5. Genes expressed in the selected pathways

\begin{tabular}{lcrcc}
\hline & & \multicolumn{2}{c}{$\begin{array}{c}\text { Genes under miRNAs } \\
\text { control }\end{array}$} \\
\cline { 3 - 5 } Pathways & $\begin{array}{c}\text { Total } \\
\text { number }\end{array}$ & Number & Percentage \\
\cline { 3 - 5 } Apoptosis & 24 & 13 & 54.2 \\
Cell cycle regulation & 14 & 8 & 57.1 \\
WNT signaling pathway & 31 & 13 & 41.9 \\
Notch signaling pathway & 7 & 2 & 28.6 \\
Hedgeogh signaling pathway & 8 & 1 & 12.5 \\
ECM receptor interaction & 36 & 21 & 58.3 \\
and cell communication & 11 & & \\
ABC transporters general & 47 & 20 & 4.1 \\
MAPK signaling pathway & 17 & 6 & 35.6 \\
Cell adhesion molecules (CAMs) & 34 & 16 & 47.1 \\
Highly de-regulated genes & & &
\end{tabular}

responsible for the stemness character of human osteosarcoma.

In our study, among the predicted miRNA-mRNA interactions, the most intriguing seemed to be those involving the down-regulated miR let-7/98 and 29a,b,c families and the up-regulated MSTN, CCND2, Lin28B, MEST, HMGA2, and GHR genes. These players, described in Figure 6 together with IGF-2, captured our attention for a large number of reasons: (I) both let-7/98 and 29a,b,c miRNAs serve as strong tumor suppressors by targeting genes that influence cell-cycle progression and apoptosis, and are strongly down-regulated in several types of cancers, thus favoring tumor progression
(Fabbri et al., 2007; Bussing et al., 2008); (2) processing of the let-7 family is blocked by Lin28B, an RNA-binding protein that when overexpressed is considered an unfavorable prognostic marker in various cancer types (Viswanathan et al., 2009);

(3) let-7/98 and Lin-28 form an autoregulatory circuit that controls miRNA processing (Rybak et al., 2008) and which is fundamental for maintaining stemness; (4) Lin28B overexpression also enhances the expression of HMGA2, an oncogene, that is, one of the major let-7/98 targets; HMGA2 is undetectable in normal adult tissues, but is widely expressed in undifferentiated embryonic tissues and cancer cells (Boyerinas et al., 2008); (5) Lin28B may also up-regulate the expression of IGF-2 (Lu et al., 2009), a normally imprinted oncogene whose loss of imprinting (LOI) has been associated with increased risks of a number of cancers, including pediatric osteosarcoma ( $\mathrm{Li}$ et al., 2009); (6) let7/98 may also regulate GHR, an oncogene that activates survival and antiapoptotic pathways and that is upregulated in a large number of cancers (Bidosee et al., 201 I); (7) let-7/98 miR family also targets CCND2, an oncogene that regulates cell-cycle progression and that is overexpressed in various cancer types, including osteosarcoma (Sarkar et al., 20I0); (8) CCND2 is also under the control of miR-29a,b,c members that strongly control the MSTN and MEST genes, two particularly interesting genes because MSTN promotes human embryonic stem cell self-renewal and potently increases in cancer cachexia (Hannan et al., 2009; Benny Klimek et al., 20 I0), while MEST is an imprinted gene whose LOI has been reported in pediatric osteosarcoma and in many other cancer types (Li et al., 2008).

The scenario described and discussed in Figure 6 suggests that the down-regulation of miR let-7/98 and miR 29a,b,c may be the cause of the up-regulation of the reported genes and highlights for the first time a regulatory network between each of them, which could be characteristic of the subpopulation of CSCs that drives tumorigenesis and chemoresistance in osteosarcoma. The findings strongly support the idea that these cells may be a valuable model for studying the origin and aggressiveness of osteosarcoma to find ways of targeting its aggressive behavior.

Currently, we are developing a new research project aimed at the functional validation of miR let-7d and miR-29b-I, and to establish their role in maintaining the stemness properties of $3 \mathrm{AB}-\mathrm{OS}$ cells.

\section{Acknowledgments}

We thank Dr. Antonio Tesoriere (Department of Economics, Business and Finance. Faculty of Economics, University of Palermo, Italy) for supplying the mathematical formula, described in Methods, which was applied in selecting miRNAs for predictive target genes. We also thank Dr. Tesoriere for

TABLE 6. Strongly down-regulated miRNAs with highly up-regulated mRNAs

\begin{tabular}{|c|c|c|c|}
\hline Gene & Fold change $\left(\log _{2}\right)$ & $P$-value & Down-regulated miRNAs predicted to target the listed genes \\
\hline $\begin{array}{l}\text { MSTN } \\
\text { CCND2 }\end{array}$ & $\begin{array}{l}8.55 \\
8.14\end{array}$ & $\begin{array}{l}6.09 \mathrm{E}-06 \\
6.09 \mathrm{E}-06\end{array}$ & $\begin{array}{c}\text { hsa-miR-29b }(-5.03) \\
\text { hsa-miR-29 a }(-4.08) \text {; hsa-miR-29b }(-5.03) \text {; hsa-let-7b }(-4.68) \text {; hsa-let-7f }(-5.15) \\
\text { hsa-let-7d }(-5.5 I) ; \text { hsa-miR-98 }(-7.91)\end{array}$ \\
\hline IGF2 & 7.09 & $6.27 \mathrm{E}-06$ & 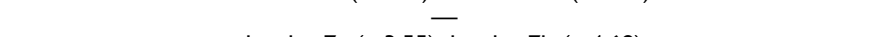 \\
\hline LIN28B & 6.87 & $6.09 \mathrm{E}-06$ & $\begin{array}{l}\text { hsa-let-7g }(-3.55) ; \text { hsa-let-7b }(-4.68) \\
\text { hsa-let-7f }(-5.15) ; \text { hsa-let-7d }(-5.5 \mathrm{I}) \\
\text { hsa-miR-98 }(-7.91)\end{array}$ \\
\hline HMGA2 & 6.71 & $6.43 \mathrm{E}-06$ & $\begin{array}{c}\text { hsa-let-7g }(-3.55) ; \text { hsa-let-7b }(-4.68) \\
\text { hsa-let-7f }(-5.15) ; \text { hsa-let-7d }(-5.5 \mathrm{I}) \\
\text { hsa-miR-98 }(-7.91) ;\end{array}$ \\
\hline MEST & 6.32 & $6.09 \mathrm{E}-06$ & $\begin{array}{c}\text { hsa-let-7g }(-3.55) ; \text { hsa-let-7b }(-4.68) \\
\text { hsa-let-7f }(-5.15) ; \text { hsa-let-7d }(-5.5 I) \\
\text { hsa-miR-98 }(-7.9 I) ; \text { hsa-miR-29a }(-4.08) ; \text { hsa-miR-29b }(-5.03)\end{array}$ \\
\hline GHR & 4.99 & $6.43 \mathrm{E}-06$ & $\begin{array}{c}\text { hsa-let-7a }(-2.83) ; \text { hsa-let-7g }(-3.55) \\
\text { hsa-let-7b }(-4.68) ; \text { hsa-let-7f }(-5.15) \\
\text { hsa-let-7d }(-5.5 \mathrm{I})\end{array}$ \\
\hline
\end{tabular}


Potential new therapeutic targets in osteosarcoma:

miRs and their predective target genes that characterize $3 \mathrm{AB}-\mathrm{OS}$ cancer stem cells

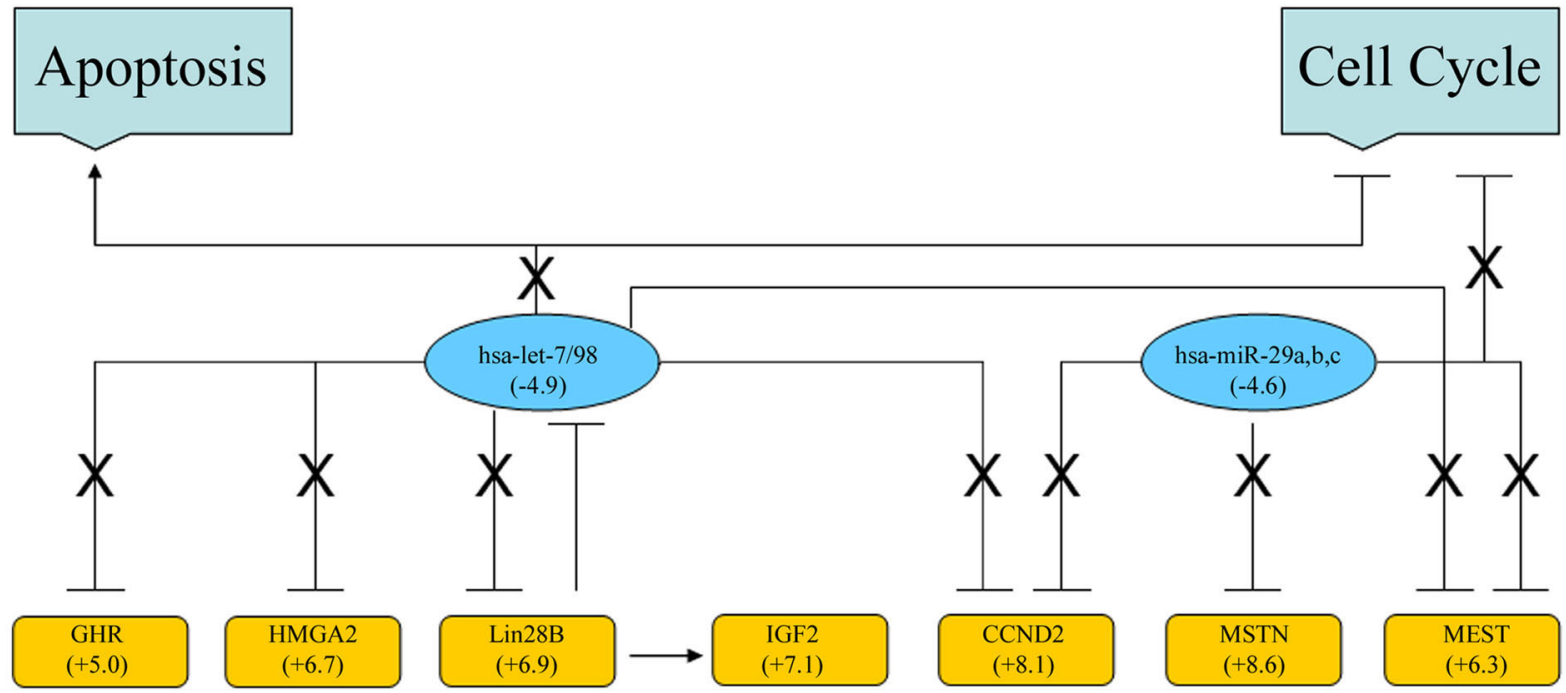

dysregulated in $3 \mathrm{AB}-\mathrm{OS}$ cancer stem cells

down-regulated miRs

up-regulated genes

Fig. 6. Functional interaction network between miRNAs and predictive antiregulated genes. Values reported in brackets represent the average gene expression values; the $X$ along the network indicates that the normal roles played by the two miR families, owing to their down-regulation, are impeded.

helpful discussions on bioinformatic and biostatistical analyses. We thank Dr. Francesca Romana Grati, Head of the Research and Development Area (Toma Advanced Biomedical Assays S.p.A., Busto Arsizio) for helpful technical discussion on karyotype and array $\mathrm{CGH}$ analyses. We are extremely grateful to Dr. Francesca Pentimalli (INT-CROM, 'Pascale Foundation', National Cancer Institute - Cancer Research Center, Mercogliano, Avellino, Italy) for insightful comments on the manuscript. We thank Dr. Antonella D'Anneo (Department of Experimental Biomedicine and Clinical Neurosciences, University of Palermo, Italy) for help in preparing the manuscript. We appreciate BioMed Proofreading for its expertise in editing the manuscript.

\section{Literature Cited}

Bapat SA. 2007. Evolution of cancer stem cells. Semin Cancer Biol 17:204-213. Bartel DP 2009. MicroRNAs: Target recognition and regulatory functions. Cell I36.215-233. Batanian JR, Cavalli LR, Aldosari NM, Ma E, Sotelo-Avila C, Ramos MB, Rone JD, Thorpe CM, Haddad BR. 2002. Evaluation of paediatric osteosarcomas by classic cytogenetic and CGH analyses. Mol Pathol 55:389-393.

Bauer HC. 1988. DNA cytometry of osteosarcoma. Acta Orthop Scand Suppl 228:1-39. Benjamini Y, Drai D, Elmer G, Kafkafi N, Golani I. 200I. Controlling the false discovery rate in behavior genetics research. Behav Brain Res 125:279-284.

Benny Klimek ME, Aydogdu T, Link MJ, Pons M, Koniaris LG, Zimmers TA. 2010. Acute inhibition of myostatin-family proteins preserves skeletal muscle in mouse models of cancer cachexia. Biochem Biophys Res Commun 391:1548-1554.
Bidosee M, Karry R, Weiss-Messer E, Barkey RJ. 20II. Growth hormone affects gene expression and proliferation in human prostate cancer cells. Int ] Androl 34:124-137. Boyerinas B, Park SM, Shomron N, Hedegaard MM, Vinther J, Andersen JS, Feig C, Xu J, Burge CB, Peter ME. 2008. Identification of let-7-regulated oncofetal genes. Cancer Res 68:2587-2591.

Bridge JA, Nelson M, McComb E, McGuire MH, Rosenthal H, Vergara G, Maale GE, Spanier S, Neff JR. 1997. Cytogenetic findings in 73 osteosarcoma specimens and a review of the literature. Cancer Genet Cytogenet 95:74-87.

Brothman AR, Persons DL, Shaffer LG. 2009. Nomenclature evolution: Changes in the ISCN from the 2005 to the 2009 edition. Cytogenet Genome Res 127:I-4.

Bussing I, Slack F], Grosshans H. 2008. let-7 microRNAs in development, stem cells and cancer. Trends Mol Med 14:400-409.

Chan JY. 201 I. A clinical overview of centrosome amplification in human cancers. Int J Biol Sci 7:1122-1144.

Chou AJ, Gorlick R. 2006. Chemotherapy resistance in osteosarcoma: Current challenges and future directions. Expert Rev Anticancer Ther 6:1075-1085.

Clarke MF, Dick JE, Dirks PB, Eaves C], Jamieson CH, Jones DL, Visvader J, Weissman IL, Wahl GM. 2006. Cancer stem cells-perspectives on current status and future directions: $A A C R$ Workshop on cancer stem cells. Cancer Res 66:9339-9344.

Cleton-Jansen AM, Anninga JK, Briaire-de Bruijn IH, Romeo S, Oosting J, Egeler RM, Gelderblom H, Taminiau AHM, Hogendoorn PC. 2009. Profiling of high-grade central osteosarcoma and its putative progenitor cells identifies tumourigenic pathways. $\mathrm{Br}$ J Cancer 101:1909-1918.

De Blasio A, Musmec MT, Giuliano M, Lauricella M, Emanuele S, D'Anneo A, Vassallo B, Tesoriere G, Vento R. 2003. The effect of 3-aminobenzamide, inhibitor of poly(ADPribose) polymerase, on human osteosarcoma cells. Int J Oncol 23:152|-1528.

De Blasio A, Messina C, Santulli A, Mangano V, Di Leonardo E, D'Anneo A, Tesoriere G Vento R. 2005. Differentiative pathway activated by 3-aminobenzamide, an inhibitor of PARP, in human osteosarcoma MG63 cells. FEBS Lett 579:615-620.

Dean M, Fojo T, Bates S. 2005. Tumour stem cells and drug resistance. Nat Rev Cancer 5:275-284.

Di Fiore R, Santulli A, Ferrante RD, Giuliano M, De Blasio A, Messina C, Pirozzi G, Tirino V, Tesoriere G, Vento R. 2009. Identification and expansion of human osteosarcoma-cancer-stem cells by long-term 3-aminobenzamide treatment. J Cell Physiol 219:301-313. 
Di Fiore R, Guercio A, Puleio R, Di Marco P, Drago-Ferrante R, D'Anneo A, De Blasio A, Carlisi D, Di Bella S, Pentimalli F, Forte IM, Giordano A, Tesoriere G, Vento R. 2012. Modeling human osteosarcoma in mice through $3 \mathrm{AB}-\mathrm{OS}$ cancer stem cell xenografts. J Cell Biochem I I3:3380-3392.

Fabbri M, Garzon R, Cimmino A, Liu Z, Zanesi N, Callegari E, Liu S, Alder H, Costinean S, Fernandez-Cymering C, Volinia S, Guler G, Morrison CD, Chan KK, Marcucci G, Calin GA Huebner K, Croce CM. 2007. MicroRNA-29 family reverts aberrant methylation in lung cancer by targeting DNA methyltransferases $3 \mathrm{~A}$ and $3 \mathrm{~B}$. Proc Natl Acad Sci U S A 104:15805-15810.

Federico M, Symonds CE, Bagella L, Rizzolio F, Fanale D, Russo A, Giordano A. 2010. R-Roscovitine (Seliciclib) prevents DNA damage-induced cyclin AI upregulation and R-Roscovitine (Seliciclib) prevents DNA damage-induced cyclin Al upregulation
hinders non-homologous end-joining (NHEJ) DNA repair. Mol Cancer 9:208.

hinders non-homologous end-joining (NHEJ) DNA repair. Mol Cancer 9:208.
Fukasawa K. 2005. Centrosome amplification, chromosome instability and cancer development. Cancer Lett 230:6-619.

Giordano A, Fucito A, Romano G, Marino IR. 2007. Carcinogenesis and environment: The cancer stem cell hypothesis and implications for the development of novel therapeutics and diagnostics. Front Biosci 12:3475-3482

Hannan NR, Jamshidi P, Pera MF, Wolvetang EJ. 2009. BMP-II and myostatin support undifferentiated growth of human embryonic stem cells in feeder-free cultures. Cloning Stem Cells I I:427-435

lorio MV, Croce CM. 2009. MicroRNAs in cancer: Small molecules with a huge impact. J Clin Oncol 27:5848-5856.

Irizarry RA, Hobbs B, Collin F, Beazer-Barclay YD, Antonellis KJ, Scherf U, Speed TP. 2003. Exploration, normalization, and summaries of high density oligonucleotide array probe level data. Biostatistics 4:249-264.

Jones KB, Salah Z, Del Mare S, Galasso M, Gaudio E, Nuovo G], Lovat F, LeBlanc K, Palatini J Randall RL, Volinia S, Stein GS, Croce CM, Lian JB, Aqeilan RI. 2012. miRNA signatures associate with pathogenesis and progression of osteosarcoma. Cancer Res 72:1865associa 1877.

Kanehisa M, Goto S. 2000. KEGG: Kyoto encyclopedia of genes and genomes. Nucleic Acids Res 28:27-30.

Kobayashi E, Hornicek FJ, Duan Z. 2012. MicroRNA involvement in osteosarcoma. Sarcoma 2012:359739.

Lagasse E. 2008. Cancer stem cells with genetic instability: The best vehicle with the best engine for cancer. Gene Ther 15:136-142

$\mathrm{Li}$ Y, Meng G, Guo QN. 2008. Changes in genomic imprinting and gene expression associated with transformation in a model of human osteosarcoma. Exp Mol Pathol 84:234-239.

Li Y, Meng G, Huang L, Guo QN. 2009. Hypomethylation of the P3 promoter is associated with up-regulation of IGF2 expression in human osteosarcoma. Hum Pathol 40:144I1447.

Lim G, Karaskova J, Vukovic B, Bayani J, Beheshti B, Bernardini M, Squire JA, Zielenska M. 2004. Combined spectral karyotyping, multicolor banding, and microarray comparative genomic hybridization analysis provides a detailed characterization of complex structural chromosomal rearrangements associated with gene amplification in the osteosarcoma cell line MG63. Cancer Genet Cytogenet 153:158-164.

Livak KJ, Schmittgen TD. 200I. Analysis of relative gene expression data using real-time quantitative PCR and the $2^{-\Delta \Delta C t}$ method. Methods 25:402-408

Lu J, Getz G, Miska EA, Alvarez-Saavedra E, Lamb J, Peck D, Sweet-Cordero A, Ebert BL Mak RH, Ferrando AA, Downing JR, Jacks T, Horvitz HR, Golub TR. 2005. MicroRNA expression profiles classify human cancers. Nature 435:834-838.

Lu L, Katsaros D, Shaverdashvili K, Qian B, Wu Y, de la Longrais IA, Preti M, Menato G, Yu H. 2009. Pluripotent factor lin28 and its homologue lin-28b in epithelial ovarian cancer and their associations with disease outcomes and expression of let-7a and IGF-II. Eur J Cancer 45:2212-2218

Maire G, Martin JW, Yoshimoto M, Chilton-MacNeill S, Zielenska M, Squire JA. 20I I. Analysis of miRNA-gene expression-genomic profiles reveals complex mechanisms of microRNA deregulation in osteosarcoma. Cancer Genet 204:138-146.

Martins-Neves SR, Lopes ÁO, do Carmo A, Paiva AA, Simões PC, Abrunhosa AJ, Gomes CM. 2012. Therapeutic implications of an enriched cancer stem-like cell population in a human osteosarcoma cell line. BMC Cancer I2:139.

Mayhew CN, Carter SL, Fox SR, Sexton CR, Reed CA, Srinivasan SV, Liu X, WikenheiserBrokamp K, Boivin GP, Lee JS, Aronow BJ, Thorgeirsson SS, Knudsen ES. 2007. RB loss abrogates cell cycle control and genome integrity to promote liver tumorigenesis. abrogates cell cycle control and

McCubrey JA, Steelman LS, Abrams SL, Misaghian N, Chappell WH, Basecke J, Nicoletti F, Libra M, Ligresti G, Stivala F, Maksimovic-Ivanic D, Mijatovic S, Montalto G, Cervello M, Laidler P, Bonati A, Evangelisti C, Cocco L, Martelli AM. 2012. Targeting the cancer initiating cell: The ultimate target for cancer therapy. Curr Pharm Des 18:1784-1795.

Niini T, Lahti L, Michelacci F, Ninomiya S, Hattinger CM, Guled M, Böhling T, Picci P, Serra M, Knuutila S. 20II. Array comparative genomic hybridization reveals frequent alterations of $\mathrm{GI} / \mathrm{S}$ checkpoint genes in undifferentiated pleomorphic sarcoma of bone. Genes Chromosomes Cancer 50:291-306.

Rainusso N, Man TK, Lau CC, Hicks J, Shen JJ, Yu A, Wang LL, Rosen JM. 20II. Identification and gene expression profiling of tumor-initiating cells isolated from human osteosarcoma cell lines in an orthotopic mouse model. Cancer Biol Ther 12:278-287.

Roschke AV, Kirsch IR. 20I0. Targeting karyotypic complexity and chromosomal instability of cancer cells. Curr Drug Targets II:|34|-1350.

Rybak A, Fuchs H, Smirnova L, Brandt C, Pohl EE, Nitsch R, Wulczyn FG. 2008. A feedback loop comprising lin-28 and let-7 controls pre-let-7 maturation during neural stem-cell commitment. Nat Cell Biol 10:987-993.

Sarkar R, Hunter IA, Rajaganeshan R, Perry SL, Guillou P, Jayne DG. 2010. Expression of cyclin $\mathrm{D} 2$ is an independent predictor of the development of hepatic metastasis in colorectal cancer. Colorectal Dis I2:316-323.

Smyth GK. 2004. Linear models and empirical bayes methods for assessing differential expression in microarray experiments. Stat Appl Genet Mol Biol 3:Article 3.

Tang N, Song WX, Luo J, Haydon RC, He TC. 2008. Osteosarcoma development and stem cell differentiation. Clin Orthop Relat Res 8:2114-2130.

Tirino V, Desiderio V, Paino F, De Rosa A, Papaccio F, Fazioli F, Pirozzi G, Papaccio G. 2011 Human primary bone sarcomas contain CDI33+ cancer stem cells displaying high tumorigenicity in vivo. FASEB J 25:2022-2030.

Visvader JE, Lindeman GJ. 2008. Cancer stem cells in solid tumours: Accumulating evidence and unresolved questions. Nat Rev Cancer 8:755-768.

Viswanathan SR, Powers JT, Einhorn W, Hoshida Y, Ng TL, Toffanin S, O'Sullivan M, Lu J, Phillips LA, Lockhart VL, Shah SP, Tanwar PS, Mermel CH, Beroukhim R, Azam M, Teixeir J, Meyerson M, Hughes TP, Llovet JM, Radich J, Mullighan CG, Golub TR, Sorensen PH, Daley GQ. 2009. Lin28 promotes transformation and is associated with advanced human malignancies. Nat Genet 41:843-848.

Wang L, Park P, Lin CY. 2009. Characterization of stem cell attributes in human osteosarcoma cell lines. Cancer Biol Ther 8:543-552.

Wang L, Park P, Zhang H, La Marca F, Claeson A, Valdivia J, Lin CY. 20I I. BMP-2 inhibits the tumorigenicity of cancer stem cells in human osteosarcoma OS99-I cell line. Cancer Biol Ther I 1:457-463.

Wettenhall JM, Simpson KM, Satterley K, Smyth GK. 2006. affylmGUI: A graphical user interface for linear modeling of single channel microarray data. Bioinformatics 22:897-899. 